\title{
The 'Rainbow Nation' way of teaching sensitivity to diversity for social work with groups
}

Reineth Prinsloo

Abstract: Because social work clients are often members of oppressed, vulnerable and disempowered groups, teaching sensitivity to diversity and empowering social work students to be culturally competent is of the utmost importance. South Africa's history of apartheid has had detrimental effects on personal, social, economic, and political development. A department of social work at a university in South Africa introduced specific study units within its Bachelor of Social Work (BSW) programme to address the influence of this particularly vicious form of discrimination. The units help students to confront their own prejudices, enhance their self-awareness, and obtain knowledge of and exposure to diverse client populations. This paper discusses the need for coursework in this area, and describes the process of teaching these study units.

Keywords: social work intervention with groups; diversity education; South African groupwork.

1. Senior Lecturer, Department of Social Work and Criminology, University of Pretoria, South Africa

Address for correspondence: Department of Social Work \& Criminology, University of Pretoria, HSB 10-9, Lynnwood Road, Pretoria 0002, Republic of South Africa. Reineth.prinsloo@up.ac.za 
'I am glad for the word apartheid'. The audience falls silent. How is it possible for a white South African woman to state this at an international symposium in the United States of America?

The liberation of South Africa from apartheid in 1994 has resulted in changes which have forced the people of this 'Rainbow Nation' towards greater tolerance and accommodation. It is the author's opinion that by openly naming, discussing, criticizing, judging, and eventually addressing apartheid, discrimination and insensitivity to cultural diversity are finally being confronted in South African society.

South Africa has eleven official languages and as many and more different cultural groups. This diversity creates many wonderful opportunities to learn about other cultures and overcome conscious or unconscious discrimination. This paper describes the specific study units developed by a department of social work at a university in South Africa to prepare their BSW students to address the influence of apartheid.

\section{The effects of apartheid}

The former National Party of South Africa, consisting mainly of white South Africans, implemented and maintained a system referred to as 'apartheid' - an extreme form of discrimination and insensitivity to diversity - from 1948 until 1994. This political party used their immense power to influence people and decide on the distribution of resources. As Mamphiswana and Noyoo (2000, p.31) emphasize, apartheid was a brutal form of colonial domination that sapped the energies of the people and eroded their self-worth. Apartheid had detrimental effects on personal, social, economic, and political development. Poverty and inequality in South Africa result from centuries of colonialism and apartheid during which indigenous populations were oppressed and their lands, productive assets, cultural heritage and self-respect severely impacted (Hölscher, 2008, pp.120-121).

South Africa has been faced with many challenges with regard to a 'new' way of functioning since the democratization in 1994. All spheres of life and social relations have been affected. While the nation has reached higher levels of liberation from apartheid since 1994, poverty, structural oppression, and power imbalances continue (Smith, 2008, p.371). 


\section{Sensitivity to diversity in social work}

Cultural diversity refers to the variety in human society and culture in a specific region - seen in aspects such as language, dress, tradition and the way people interact with their environment. Unfortunately, human beings often respond to diversity with conscious or unconscious discrimination. Discrimination and abuse of power are worldwide phenomena. As defined by Zastrow (2009, p.198), discrimination means taking action against people because they belong to a specific category of people. Such behaviour is unethical. Although there are different views about specific social work values and principles, most reflect the acceptance and positive evaluation of diverse ways of life (Wilson et al., 2008, p.83).

Failing to recognise the reality of all people, but especially a disadvantaged or socially excluded person, may in itself be regarded as oppression (Wilson et al., 2008, p.83). Miley et al. (2009, p.94) regard oppression as the injustice that results from domination and control of resources by favoured groups. Social work deals with clients that are oppressed, disempowered and vulnerable. This necessitates that social workers should confront the multiple dimensions of oppression (Miley et al., 2009, pp.95-96), understand the world of the powerless, and not contribute to oppression in any way.

Populations served by social workers cut across diverse sociocultural contexts. Social workers need a depth of knowledge and skills to intervene with sensitivity (Carter-Black, 2007). Cultural competence and a practical familiarity are of the utmost importance to maintain high standards in service delivery (Corey \& Corey, 1996, p.28; Carter-Black, 2007, p.31; Allen-Meares, 2007, p.83). Social workers with a culturally sensitive approach appreciate clients' uniqueness (Miley et al., 2009, p.70). Acceptance of and respect for this uniqueness are necessary for competence.

\section{Sensitivity to diversity in groupwork}

Konopka (1983) suggests that the following values related to diversity are important in groupwork practice: 
1. positive relations and participation among people of different colour, creed, age, national origin and social class;

2. a high degree of individualization so that every member's unique concerns are addressed.

Group leaders often work with group members from diverse backgrounds. The Standards for social work practice with groups, developed by the Association for the Advancement of Social Work with Groups (1998), emphasizes that a core value of groupwork practice is respect for persons and their autonomy. Groupworkers must place a high value on respect for diversity in all its dimensions, including culture, ethnicity, gender, sexual orientation, physical and mental abilities, and age (Johnson \& Johnson, 2003, p.479). They should appreciate and understand the differences among members, and between members and the groupworker, that may influence practice. Effective groupwork practice calls for cultural competence.

No matter how stigmatized group members may be by society, they deserve to be treated with respect and dignity. Groupwork should facilitate understanding and camaraderie among people from diverse backgrounds (Toseland \& Rivas, 2009, p.8). Effective counsellors learn how to recognize diversity and shape their intervention according to the world of a group member. Lordan and Wilson (2002, p.11) emphasize the importance of naming differences as a first step to understanding them. Identifying and engaging differences from the beginning of the group create opportunities for better understanding and intervention. Doel (2006, p.143) emphasizes that it is likely that there will be different values within every group and that denying or suppressing differences will not make them disappear.

Not only should groupworkers help members to recognize differences and understand them, but they should also recognize and understand their own values and differences. As Marsiglia (2003, p.84) points out, groupworkers' world views, beliefs and values influence their practice. A groupworker has to be clear about his or her own values and perceptions before attempting to engage with others.

Culturally skilled groupworkers will move away from their own values and prejudices to understand the world of their group members. It is, however, not possible to do so without understanding their own 
cultural conditioning and family of origin beliefs, as well as the sociopolitical systems that they are part of. Family of origin provides the foundation of culture, gender expectations, and general perceptions of society (Waldegrave, 2009, p.86). For example, the political system in South Africa dictated and ascribed certain values and prejudices to different groups, regardless of individual differences, and this was conveyed in the context of the family of origin.

If groupworkers are not aware of their own values, they will have difficulty when faced with value-laden situations. Exercises to clarify values can help groupworkers to identify personal and professional values that may influence their groupwork practice. Supervision can also help groupworkers to become aware of their own values, and to modify or change values that are neither consistent with the values of the social work profession nor helpful in their groupwork practice.

Members who reflect on and recognise their own culture are more likely to participate and to benefit from intervention (Marsiglia, 2003, p.85). Groupworkers should be aware of the cultural backgrounds of group members, and how their backgrounds affect their attitudes about sharing personal information with persons outside the family or their culture (Henry, 1992). Groupworkers also need to be sensitive to the effects that cultural diversity have on valued behaviour in the group. Culture influences beliefs about social distance, the appropriate way to speak, the proper treatment of persons in authority positions and certain age groups, and the correct way to address persons from other cultural or age groups.

Sensitivity to all of these factors requires knowledge with regard to the values of different cultural groups. A group leader should understand the different cultures of group members as well as how these cultures affect participation in group contexts (Jacobs et al., 2009, p.140; Zastrow, 2009, p.215).

\section{The role of social work education}

Preparing social work students to conduct their practice with respect for diversity and sensitivity to discrimination has been a long-standing objective of social work education. Social work programs across the globe have a responsibility to teach sensitivity to diversity in order to 
prepare social workers to address inequality and help vulnerable groups affected by skewed power and racism. This holds especially true for teaching social work in post-apartheid South Africa.

Collective social responsibility is necessary in order to overcome the legacy of apartheid. Social work holds an excellent position in such collective efforts.

Social work has ... a major role in rejuvenating the spirit of self-worth, especially amongst the African communities who were brutalized both physically and mentally by apartheid for many years (Mamphiswana $\&$ Noyoo, 2000, p.31).

Erasmus (2006) in Leibowitz et al. (2007, p.703) argues that race, as well as identity based on racial perceptions, influences the lives of South African students. Since social work students enter the field of study from a specific historical and rational context of racial discrimination, it is imperative that social work teachers stimulate the process of critical reflection (Smith, 2008, p.374).

The department of social work in a university in South Africa has developed a program to teach sensitivity to diversity. The department has a diverse student population, including individuals from the different cultural and ethnic groups. These students are exposed to equally diverse client groups in their social work practice. Cultural sensitivity is thus of the utmost importance.

\section{Teaching diversity in a South African BSW programme}

This paper describes how groupwork is used for teaching sensitivity to diversity in a BSW programme within a department of social work in a South African university.

The first year practice module aims to enhance understanding and sensitivity to diversity. In order to accomplish this goal, lecturers purposefully divide students into small groups, based on gender and cultural/ethnic diversity. They attempt to ensure that practice groups include both male and female students from different ethnic backgrounds. Within these groups, students identify and discuss their individual cultural practices, with an emphasis on being sensitive and 
respectful to fellow learners. The importance of cultural sensitivity in social work practice is discussed.

Social work students receive the opportunity to gain knowledge in group supervision and discussion classes when talking about rituals and practices in their cultures. relationship building rituals, wedding practices, funeral rituals and methods of communication are discussed. Students become aware of dowry practices in modern times; the management of marital conflict in traditional families; extended family practices; the use of eyes in communication to reflect respect; and norms for addressing someone older than oneself.

A handshake is very important in African greetings and is done in a specific way. Students unfamiliar with the handshake learn how to greet in the appropriate way, while the students teaching their peers feel privileged to do so. Greetings in the different languages are practiced. This exercise results in laughter and bonding at the same time, as students struggle to pronounce the words correctly. Students are encouraged to greet each other in the different languages outside the classroom setting. It is clear that they enjoy learning how to greet in a different language, but what is even more important is that the students being greeted in their own language feel valued and understood. Students are also encouraged to enquire about the origin and meaning of each other's names. Showing interest in another's name makes a person feel respected and valued.

Animals have many meanings in Africa, and certain animals signify certain character qualities. Some cultures view owls as bad omens, rather than as embodiments of wisdom and intelligence. A baboon may be regarded as an evil spirit and even be linked to witchcraft. A chameleon may be associated with witchcraft because of its ability to change colour. Students need to have knowledge of these meanings in order to intervene in a sensitive way. In conversations, exercises, and classroom discussions they learn to be sensitive to the use of animal metaphors.

Exercises to discuss the above cultural practices and meanings are included in the study units. Experiences are reflected in narrative reports and, where necessary, discussed in supervision. Students openly admit their ignorance about other cultures and aspects of diversity and are excited to learn about each other's cultures.

Feedback from students includes the following comments: 
1. 'I now understand the emphasis on getting engaged and having an engagement ring. I thought it was just to show off and never knew that it was an expectation.'

2. 'I am glad that I do not have to be present when the bridegroom slaughters a cow but now understand that it is a cultural ritual. The colourful wedding process to incorporate western and traditional practices amazes me. I wish that I can have the opportunity to be invited to such a wedding.'

Teaching sensitivity to diversity intensifies in the second year of the programme and focuses on self-development. Within small groups, students further identify diverse cultural practices amongst themselves and in the community. These groups are again purposefully composed to be culturally/ethnically diverse. Students are asked to confront their own personal stereotypes and prejudices. Lecturers facilitate the development of awareness and mutual understanding of group members' cultural practices.

Class exercises to clarify values can help students to identify personal and professional values that may influence their practice. They examine their own personal backgrounds and socialization experiences, consider personal manifestations of prejudice, and then list ways to overcome their prejudices.

Students discuss specific scenarios where cultural and religious diversity are prominent. An example of such a scenario is one in which a black farm worker is killed by both a white and a black man and then fed to a lion on the farm. What do students see when they first read the headline? A white man killed a black man? A white man and a black man committed murder? Just a brutal murder?

A second example involves a single sex white couple wanting to adopt a black AIDS orphan. Do students first see that this couple is single sex? Do they see a white couple wanting to adopt a black baby? Do they see the selfless act of providing a home to an orphan?

In response to these scenarios students, within two-hour classes, identify and reflect upon their own prejudices and identify areas for change and growth. Their responses include:

1. 'When I first read the scenario I saw a black farm worker killed by 
a white man. When I read it again and we discussed it in class I realised that it was murder and had nothing to do with race. I realise that my family background and the way I was raised make me to sometimes respond with the looking glass of prejudice, induced by my family that suffered because of apartheid. I have to change my own way of thinking. I cannot react this way as a social worker.'

2. 'Perhaps the white man used the black man to do his dirty work. No, they both killed a man. This has nothing to do with skin colour and I may not think this way. Murder is wrong!'

3. 'HIV/AIDS is such an enormous problem and children do not ask to be influenced. Anyone that can provide a home, love and care should do so. Sexual preferences and ethnic group play no role.'

4. 'I will gladly assist in facilitating adoption of orphans because of the pandemic, regardless of diversity.'

5. 'How can I be so stuck on skin colour? Are we not all the same human beings with similar feelings? Apartheid was so wrong.'

Students indicate that confronting and discussing these scenarios, although disturbing, forces introspection and change. They report enhanced awareness of their own beliefs, prejudices, and values.

Each second year student is required to conduct and record an interview with a person who has a sexual, cultural or religious orientation, which is different from his or her own. Lecturers assess the contribution of the interview to the student's own sensitivity to diversity. Student comments include: 'I have never thought that a person of that religion experienced so much stigmatization, even here on campus. The interview made me realise that I should not do the same and never judge. I have to respect people's preferences' and 'The person from the interview could not thank me enough for asking and showing interest. He thinks that everyone should be willing to gain knowledge to understand and not to judge without knowing.'

During the second year, students reflect on their self-development in reports of their growing awareness, insight, and self-confidence. They are also expected to demonstrate the ability to internalise their new skills and knowledge in everyday practice and in professional conduct during class exercises.

The theory module for social work intervention with groups provides the basis for the practice training which follows. Students work in task 
groups and discuss approaches to multi-cultural groupwork, as well as ways for the groupworker to intervene with sensitivity to issues of diversity in the group. All students in the task groups, in turn, discuss their ethnic backgrounds. They discuss how their heritage might influence participation in a group. They also discuss how demographic variables such as age, gender, education, or socio-economic status influence the behaviour of group members. A volunteer within the task group discusses an incident in which he/she experienced prejudice or discrimination (prejudice could occur because of many characteristics, such as age, race, gender, or disability).

The study unit on self-development comes together in a practice experience in which students demonstrate their sensitivity to diversity by conducting life-skills groups with first year students from diverse backgrounds.

Finally, students complete an assignment involving sketching a possible diversity scenario for a treatment group. They are required to discuss one of the eight ways proposed by Toseland and Rivas (2009, pp.139-146) in which the group leader can intervene with sensitivity to issues of diversity in the group:

1. Using social work values and skills

2. Using a strength perspective

3. Exploring common and different experiences among group members

4. Exploring meanings and language

5. Challenging prejudice and discrimination

6. Advocating for members

7. Empowering members

8. Using culturally appropriate techniques and program activities

This final assignment contributes to students' ability to make connections between theory and their practice experience. Second year social work students consistently reflect that the learning modules just described empower them to broaden their frame of reference and knowledge base. 


\section{Conclusion}

Diversity provides many opportunities for the enrichment of society, but we can only take advantage of these opportunities if we embrace it with sensitivity and respect. In every society, social work plays a major role in contributing to an environment that works toward this goal. The study modules discussed in this paper are one attempt to address the need to prepare social work students in South Africa to address the critical issues of diversity in a post-apartheid society. In an increasingly global world, it is imperative that we share our strategies for teaching this critical aspect of social work and groupwork practice with the next generation. If we embrace diversity with the necessary sensitivity and respect and humbly acknowledge our differences, we realise that these differences create a unique rainbow.

\section{References}

Allen-Meares, P. (2007). Cultural competence: An ethical requirement. Journal of Ethnic and Cultural Diversity in Social Work, 16, 3, 83-92

Association for the Advancement of Social Work with Groups. (1998). Standards for Social Work Practice with Groups. Akron, OH: AASWG

Carter-Black, J. (2007). Teaching cultural competence: An innovative strategy grounded in the universality of storytelling as depicted in African and African American storytelling traditions. Journal of Social Work Education, 43, 1, 31-50 Corey, M.S. and Corey, G. (2006). Groups. Process and practice. USA: Brooks/Cole. Doel, M. (2006). Using Groupwork. London: Routledge

Henry, S. (1992). Group Skills in Social Work. A four-dimensional approach. $\left(2^{\text {nd }}\right.$ ed.) Pacific Grove: Brooks/Cole

Hölscher, D. (2008). The Emperor's new clothes: South Africa's attempted transition to developmental social welfare and social work. International Journal of Social Welfare, 17, 114-123

Jacobs, E.E., Masson, R.L. and Harvill, R.L. (2009). Group Counselling: Strategies and skills. ( $6^{\text {th }}$ ed.) Belmont: Thomson Brooks/Cole.

Johnson, D.W. and Johnson, F.P. (2003). Joining Together. Group theory and group skills. ( $8^{\text {th }}$ ed.) Boston: Allyn and Bacon

Konopka, G. (1983). Social Group Work: A helping process, (3 ${ }^{\text {rd }}$ edn). Englewood Cliffs, NJ: Prentice-Hall 
Leibowitz, B., Rohleder, P., Bozalek, V., Carolissen, R. and Swartz, L. (2007).

'It doesn't matter who or what we are, we are still just people': Strategies used by university students to negotiate difference. South African Journal of Psychology, 37, 4, 702-719

Lordan, N. and Wilson, M. (2002). Groupwork in Europe: tools to combat social exclusion in a multicultural environment. In S. Henry, J. East, and C. Schmitz, (Eds.), Social work with groups. Mining the gold. New York: Haworth Press (pp.9-30)

Mamphiswana, D. and Noyoo, N. (2000). Social work education in a changing socio-political and economic dispensation. Perspectives from South Africa. International Social Work, 43, 1, 21-32

Marsiglia, F.F. (2003). Culturally grounded approaches to social justice through social work with groups. in N. Sullivan, E.S. Mesbur, N.C. Lang, D. Goodman, and L. Mitchell (Eds.), Social Work with Groups. Social justice through personal, community, and societal change. New York: Haworth Press, 79-90 Miley, K.K., O'Melia, M. and DuBois, B. (2009). Generalist Social Work Practice: An empowering approach. (6 ${ }^{\text {th }}$ ed.) Boston: Pearson Education

Smith, L. (2008) South African social work education: Critical imperatives for social change in the post-apartheid and post-colonial context. International Social Work, 51, 3, 371-383

Toseland, R.W. and Rivas, R.F. (2009). An Introduction to Group Work Practice. (6 $6^{\text {th }}$ ed.) Boston: Allyn and Bacon

Waldegrave, C. (2009). Cultural, gender, and socioeconomic contexts in therapeutic and social policy work. Family Process, 48, 1, 85-101

Wilson, K., Ruch, G., Lymbery, M., and Cooper, A. (2008). Social Work. An introduction to contemporary practice. Essex: Pearson Longman.

Zastrow, C.H. (2009). Social Work with Groups. A comprehensive workbook. ( $7^{\text {th }}$ ed.) Belmont: Thomson Brooks/Cole

Note: This article is based on a presentation at the 31st Annual International Symposium Association for the Advancement of Social Work with Groups, Chicago, Illinois, June 27th, 2009. It is also included in the collected proceedings of the Symposium (Bergart, A.M., Simon,S.R., and Doel, M.(Eds.) (2012) Group Work: Honoring our Roots, Nurturing our Growth. London: Whiting \& Birch). 